\title{
QR
}

Universität Regensburg

\section{Context-dependent third-party intervention in agonistic encounters of male Przewalski horses}

\section{Short title: Third-party intervention in Przewalski horses}

\author{
Konstanze Krueger ${ }^{13}$; Gudrun Schneider ${ }^{2}$; Birgit Flauger ${ }^{1}$, Dr.; Jürgen Heinze ${ }^{1}$ \\ ${ }^{1}$ University of Regensburg, Biology 1, Universitätsstraße 31, 93053 Regensburg, Germany \\ ${ }^{2}$ Ernst-Moritz-Arndt University of Greifswald, Zoological Institute \& Museum, Germany \\ present address: \\ ${ }^{3}$ University of Applied Sciences Nürtingen-Geislingen, Neckarsteige 6-10, 72622 Nürtingen, Germany \\ corresponding author: Konstanze Krueger: konstanze-krueger@equine-science.de
}

'The original publication is available at http://www.sciencedirect.com December 2015

Behavioural Processes doi:10.1016/j.beproc.2015.10.009

\section{Abstract}

One mechanism to resolve conflict among group members is third party intervention, for which several functions, such as kin protection, alliance formation, and the promotion of group cohesion have been proposed. Still, empirical research on the function of intervention behaviour is rare. We studied 40 cases ofintervention behaviour in a field study on 13 semi-wild bachelor horses (Equus ferus przewalskii) in (a) standard social situations, and (b) when new horses joined the group (i.e. introductions). Only interventions in agonistic encounters were analysed. Eight of 13 animals directed intervention behaviour toward threatening animal in agonistic encounters of group members. One stallion was particularly active. The stallions did not intervene to support former group mates or kin and interventions were not reciprocated. In introduction situations and in standard social situations, the interveners supported animals which were lower in rank, but targeted, threatening animals of comparable social rank. After introductions, stallions received more affiliative behaviour from animals they supported and thus appeared to intervene for alliance formation. In standard social situations, interveners did not receive more affiliative behaviour from animals they supported and may primarily have intervened to promote group cohesion and to reduce social disruption within the group.

\section{Keywords}

Equus ferus przewalskii; Group conflict; Rank orders; Social bonds; Social control; Third-party intervention

\section{Introduction}

Conflict among individual group members poses a severe threat to the cohesiveness and integrity of social groups and therefore needs to be resolved (Bernstein, 1976; de Waal, 1977; Ehardt and Bernstein, 1992; Flack et al., 2005, 2006). Third-party interventions may provide one of several ways to maintain group stability (Aureli and de Waal, 2000; Smith et al., 2010), when interveners interrupt interactions between initiators and recipients through direct physical contact, interposition, or threats (Widdig et al., 2006; Jennings et al., 2009; Smith et al., 2010; Fig. 1). Especially when animals intervene in agonistic encounters of group members, third-party intervention is potentially costly for the intervener, who risks physical injury and invests energy and time in scanning group behaviour (Clutton-Brock, 2009; Smith et al., 2010). Nevertheless, the consistent and widespread occurrence of this behaviour in numerous species of animals including humans suggests that interveners benefit from their behaviour. Benefits may be indirect and direct fitness gains.

First, interveners which support distinct animals may support or protect kin, as in primates (Hamilton, 1964; Gouzoules and Gouzoules, 1987) and spotted hyenas (Crocuta crocuta) (Zabel et al., 1992; Smith et al., 2010). Second, animals may attempt to secure the reciprocation of aid for future encounters from the individual they support through intervention (Trivers, 1971), as shown in many primate species (de Waal and Luttrell, 1988; Silk, 1992; Schino et al., 2007), as well as in coaties (Romero and Aureli, 2008). Third, by supporting particular animals interveners may support or win alliance partners, as in male baboons (Papio spp.), female rhesus macaques (Macaca mulatta, Noë et al., 1991; Noë, 1992 , Noë and Hammerstein, 1994, 1995), spotted hyenas (Crocuta crocuta) (Zabel et al., 1994; Smith et al., 2010), zebras (Equus quagga, Schilder, 1990) and domestic horses 
(Equus caballus, VanDierendonck et al., 2009; Schneider and Krueger, 2012; Granquist et al., 2012). The formation of alliances is a frequent strategy in group living animals to gain mutual access to resources, such as grooming partners, mating partners, food, shelter, etc. (Noë and Hammerstein, 1994; Connor, 1995, Schülke et al., 2010; Schneider and Krueger, 2012), to reduce predation pressure and to improve reproductive success (Cameron et al., 2009). Interventions of the first three causalities may be displayed by animals of any social rank as described for chimpanzee females, which were of middle rank (de Waal, 1982).

Fourth, middle to high ranking animals may intervene in agonistic encounters of group members without supporting specific animals. This may promote group cohesion (Bernstein, 1976; Ehardt and Bernstein, 1992) through reducing tension (de Waal, 1977) and social disruption within the group (Flack et al., 2005, 2006; Jennings et al., 2009, von Rohr et al., 2012) and stabilize the group's social rank order (Packer, 1977; Flack et al., 2005, 2006). We would expect that only a few group members intervene in agonistic encounters of group members, as they run high risks of physical injury (Frank, 1996). Indeed, in primates, including humans, only certain members of a social group take over the social role of an intervener (i.e. specified social context; Hinde, 1978; Ehardt and Bernstein, 1992; Salmivalli et al., 1996; Flack et al., 2005, 2006, on Rohr et al., 2012). Such interveners may engage exceedingly in social activities of the group, as suggested by Granquist et al., 2012.

Here, we study interventions in agonistic encounters among 13 stallions in a semi-wild bachelor group of Przewalski horses (Equus ferus przewalskii) kept in seminatural conditions in Tennenloher Forst, Germany. In horses, male offspring disperse from their natal groups, either singly or together with related and unrelated group mates (Tilson, 1988; Houpt and Boyd, 1994; Zharkikh and Andersen, 2009). They remain in bachelor groups until maturity. When mature stallions take over harems, they guard the harem mares and their offspring (Berger 1986). Przewalski horses have been observed to support individuals that are attacked by other group members (Tilson, 1988; Houpt and Boyd, 1994; Zharkikh and Andersen, 2009). It was suggested that interveners benefit through kin protection (Boyd, 1988; Houpt and Boyd, 1994; Zharkikh and Andersen, 2009) or alliance formation (Tilson, 1988).

For the present study, interactions were recorded both in standard social situations and during the introduction of new animals. We predicted that:

(a) only a few group members display interventions (de Waal, 1982; Clutton-Brock and Parker, 1995; Flack et al., 2005, 2006; von Rohr et al., 2012),

(b) interveners protect former field-mates with whom they might have formed short term alliances for protecting themselves or their resources in the past, but they do not support kin. This is because horses recognize and memorize individual group mates (Proops et al., 2009; Krueger and Flauger, 2011), but have never been shown to recognize unfamiliar kin,

(c) intervention is not reciprocal, as reciprocal aid has not been shown in horses or other ungulates (Jennings et al., 2009),

(d) interveners are of high social rank and rise faster in the social hierarchy than the animals they target (de Waal, 1992; Clutton-Brock and Parker, 1995; Flack et al., 2005, 2006),

(e) interveners are highly social (Granquist et al., 2012) and exchange more affliative than agonistic behaviour with their group members,

(f) interveners preferentially support alliance partners or intervene to form long lasting alliances for future, mutual resource protection (de Waal, 1992; VanDierendonck et al., 2009; Schneider and Krueger, 2012; Granquist et al., 012).

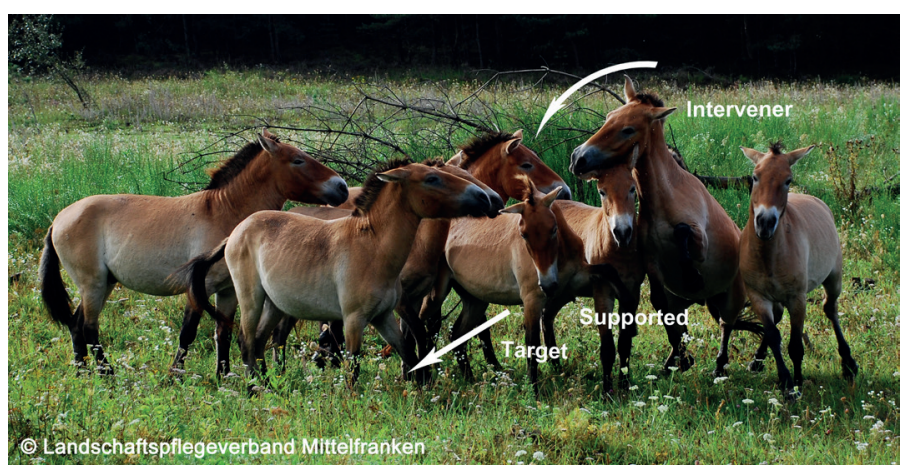

Fig. 1. 3rd party intervention.

The picture shows an agonistic encounter in a high aggression situation when a new horse joined the group. An intervening horse (i.e. the intervener) supports a recipient of a front leg kick (i.e. the supported, the new horse) by threatening the initiator of the encounter (i. e. the target). Arrows depict the movement direction of the third-party intervention participants.

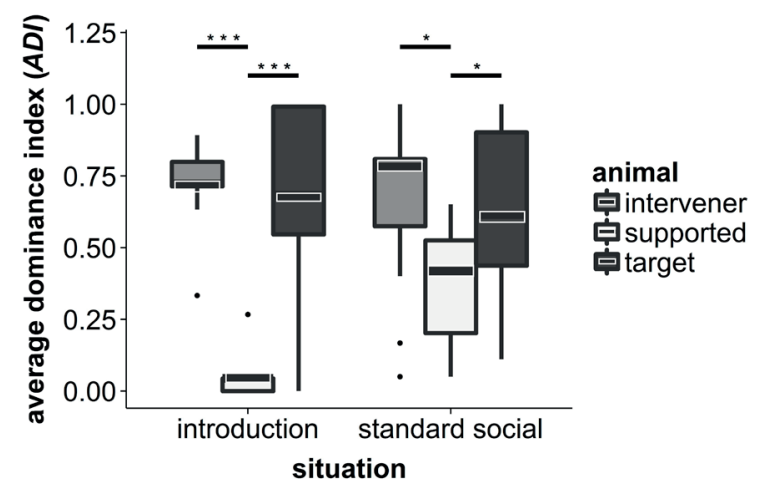

Fig. 2. Differences in social rank between intervener, supported and targeted animals.

The rank was calculated from an average dominance index (ADI). Boxplots show the median, interquartile range, minimum, maximum and outliers (dots). Social ranks between intervener and supported horses differ for introduction and standard social situations. ${ }^{* * *} \mathrm{P}<0.001,{ }^{*} \mathrm{P}<0.05$ (after sequential Bonferroni correction). 


\section{Material and Methods}

\subsection{Animals and enclosure}

We observed 13 male wild horses (Equus ferus przewalskii) kept by Landschaftspflege-verband Mittelfranken in semi-wild management in a 50ha enclosure of forest and grassland in Tennenlohe near Erlangen, Germany. They had free access to water, vegetation, and received additional hay and horse feed in winter. For controlling the horses' well-being, they were observed by park rangers daily.

The horses had been raised in the zoos of Nuremberg and Munich, Germany, and were transferred to the enclosure when they were one or two years old, and stayed there until maturity. During the study period the ages of the individuals ranged between 1 and 8 years (table 2). At the study area the horses formed one group, consisting of six to ten individuals and changing in composition due to immigrations (5 horses) and emigrations (6 horses) during the observation period. New males were introduced, singly or in pairs in April 2008, May 2009, June 2009 and July 2009. Twelve of the observed horses were related to up to three others (table A.1) and five horses were familiar with one or two other horses from their previous housing (table A.2). Pairs of horses for which familiarity status was unknown were excluded from the analysis of the effect of familiarity on interventions.

The composition and size of the study group resembled that of unstable, feral bachelor horse groups (Tyler, 1972; Berger, 1986; Tilson, 1988; Houpt and Boyd, 1994; Linklater et al., 2000), where male horses switch between staying with harems or bachelor groups. Usually immature males join a bachelor group between the ages of 1 to 3 years. Of those, some change bachelor groups frequently and others are rather resident. Other immature males stay with their natal harem, and some mature males even join a bachelor group after giving up a harem (Feh, 1999, 2005; Linklater, 2000). In the present management scheme, males were removed from the group when they started fighting at a level that could result in severe injuries or even death. In nature, such heavy fights indicate an imminent separation of maturing youngsters from the group (Houpt and Boyd, 1994; Zharkikh and Andersen, 2009).

\subsection{Study period}

From April 2008 till May 2010 we observed the group over a) nine 'standard social situations', i.e., when group membership were stable for at least 6 weeks, and during b) four 'introductions' of new individuals (table 1)

In standard social situations (table 1), behaviour was observed by continuous ad libitum sampling for 4 hours each, distributed over the daylight hours of one day. Some observations had to be stopped earlier, if the horses disappeared into the forest and were not seen again before sunset (exact observation times see table 1). In total, we observed behaviour during 'standard social situations' for 29.5 hours and in additional 25 focal video recordings, made by the rangers ( 5.5 hours in total).

In introduction situations (table 1), we conducted continuous, focal observations of the new horse and their interactions with group members for 2 hours on 4 occasions ( 8 hours in total), as aggression levels usually declined 2 hours after introducing a new group member. In these situations, the majority of the group's interactions were recorded by focusing on the new animals, as resident horses concentrated their interactions on the newcomer. Horses were individually identified by body coloration and shape. Observations were started when all group members were visible and when the horses were calm and grazing. When the group split up (in two standard social situations) we observed both subgroups for equal time periods. If necessary, binoculars were used for observation. Three observers participated in each observation, so that two observers could assist each other with distinguishing individuals and determining behaviours while the third was taking notes. Introductions of new horses were additionally video-recorded by a fourth person. Video recordings were analysed by two separate observers, who agreed on whether behaviours could be termed "intervention behaviour" in $96 \%$ of the cases. The interventions with mutual agreement were included in the study.

\subsection{Behaviour}

\subsubsection{Social Behaviour}

In standard social situations and in introduction situations, we observed agonistic behaviour, such as threats to bite, threats to kick, bites, kicks, chases, retreats, and approaches (with a subsequent retreat by the approached animal), as well as affiliative behaviour, such as grooming, grooming approaches (one animal approaching another preceding mutual grooming), mutual approaches (both animals approach each other), or neutral approaches (one animal approaching another without the approached animal making any perceptible response) (Feist and McCullough, 1976; McDonnell and Haviland, 1995).

The reaction of the receiving animal was decisive in designating behaviour as agonistic or affiliative. For example, responding to mutual, neutral, and grooming approaches by ignoring or reciprocating the approach, or beginning to groom the approaching horse were considered as affiliative (Silk et al., 2003; Cameron et al., 2009), whereas approaches that elicited a retreat by the approached individual were categorized agonistic.

\subsubsection{Intervention Behaviour}

An intervention was counted when an interaction between two horses was terminated by the aggression (threat, bite, kick or chase) or approach of a third horse (Jennings et al., 2009; Ward et al., 2009), in standard social situations and in introduction situations. As opposed animals retreated from approaching interveners in "successful interventions", the intervention approaches can be determined to be agonistic (see section 1.3.1.). For each case of intervention behaviour we noted down the triad of interacting animals, the intervener (the focus animal), the supported horse and the targeted horse. Only the threatening horses, the 
target of the intervention, was opposed and, thereafter, retreated from the intervener. The other one was supported by the intervener. For a clear distinction of intervention behaviour, only successful interventions were counted. The behaviours and social relationships of the triad participants were compared for the analysis. Figure 1 depicts an intervention in an agonistic encounter.

\subsection{Dominance hierarchies}

We calculated the dominance hierarchy among the horses from their agonistic encounters for each 'standard social situation'. Individual dominance scores were quantified by an average dominance index (ADI), chosen for its reliability and computational simplicity (Hemelrijk et al., 2005). The ADI was calculated as follows: the dominance index per pair of individuals, wij, is the number of interactions (x), in which an individual (i) won against a certain opponent (j) divided by the total number of agonistic interactions in which the pair was involved with each other (xij + xji: wins

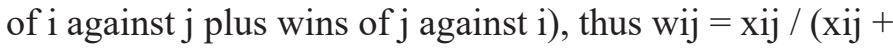
xji). If a pair of individuals was not involved in agonistic interactions with each other, it was excluded from the analysis. The average dominance index of an individual is the average of all its dominance indices with all its interaction partners, $1 / \mathrm{N} \Sigma \mathrm{j}$ wij. A higher value indicates a higher dominance status in the group (Hemelrijk et al., 2005).

The reaction of the receiver and not the type of agonistic behaviour of the attacker is decisive for counting wins and losses. For example, an animal may respond by retreating whether it is being kicked or approached. In both cases, the receiver "loses" and the initiator "wins." This method allows using all types of agonistic behaviour, irrespective of their frequency, and provides the largest possible sample size for the dominance calculation (Hemelrijk et al., 2005). For comparing social ranks we had to account for the fact that the horses of the present long-term study differed in their potential to rise in rank. Horses rise in rank with increasing age and time of residency in the group (Tilson, 1988; Houpt and Boyd, 1994; Zharkikh and Andersen, 2009). The study horses joined the group for unequal time periods. We therefore analysed the relative rank changes in terms of calculating an ADI change for each horse per month, by analysing the ADI difference from the time the animal joined the group until it departed and divided it by the corresponding number of months of this time period.

Table 1

Observation dates, observation durations, the horses' presence in the group and their individual, total interventions into agonistic encounters (dates when new group members arrived were depicted in bold).

\begin{tabular}{|c|c|c|c|c|c|c|c|c|c|c|c|c|c|c|}
\hline Date & Duration & Artos & Chatgul & Dimitri & Salu & Santos & Fajacho & Friso & Aytan & Gismo & Branai & Sittko & Galwan & Galsar \\
\hline April 08 & $4 \mathrm{~h}$ & 0 & 0 & 0 & 0 & 0 & 0 & 0 & 0 & NA & NA & NA & NA & NA \\
\hline April 08 & $2 \mathrm{~h}$ & $\mathbf{0}$ & 7 & 9 & 1 & $\mathbf{0}$ & $\mathbf{0}$ & $\mathbf{0}$ & $\mathbf{0}$ & $\mathbf{0}$ & NA & NA & NA & NA \\
\hline June 08 & $4 \mathrm{~h}$ & 0 & 0 & 0 & 0 & 0 & 0 & 0 & 0 & 0 & NA & NA & NA & NA \\
\hline August 08 & $2 \mathrm{~h}$ & 0 & 0 & 0 & 0 & 0 & 0 & NA & 0 & 0 & NA & NA & NA & NA \\
\hline November 08 & $4 \mathrm{~h}$ & 1 & NA & 4 & 0 & 0 & 0 & NA & 0 & 0 & NA & NA & NA & NA \\
\hline April 09 & $4 \mathrm{~h}$ & NA & NA & 1 & 0 & 0 & 0 & NA & 0 & 0 & NA & NA & NA & NA \\
\hline May 09 & $2 \mathrm{~h}$ & NA & NA & $\mathbf{0}$ & $\mathbf{0}$ & $\mathbf{0}$ & 1 & NA & 0 & 0 & 0 & NA & NA & NA \\
\hline June 09 & $2 \mathrm{~h}$ & NA & NA & $\mathbf{0}$ & $\mathbf{0}$ & 3 & $\mathbf{0}$ & NA & 2 & $\mathbf{0}$ & $\mathbf{0}$ & $\mathbf{0}$ & NA & NA \\
\hline June 09 & $2 \mathrm{~h}$ & NA & NA & 0 & 0 & 1 & 0 & NA & 1 & 0 & 0 & 0 & NA & NA \\
\hline June 09 & $2 \mathrm{~h}$ & NA & NA & 4 & $\mathbf{0}$ & $\mathbf{0}$ & $\mathbf{0}$ & NA & 1 & $\mathbf{0}$ & $\mathbf{0}$ & $\mathbf{0}$ & $\mathbf{0}$ & $\mathbf{0}$ \\
\hline September 09 & $2 \mathrm{~h}$ & NA & NA & 0 & 0 & 0 & 0 & NA & 0 & 0 & 0 & 0 & 0 & 0 \\
\hline 0kt. 09 & $2 \mathrm{~h}$ & NA & NA & 0 & 0 & 0 & 0 & NA & 0 & 0 & 0 & 0 & 0 & 0 \\
\hline Videos August 09 & $5 \mathrm{~h}$ & NA & NA & 0 & 0 & 0 & 0 & NA & 0 & 0 & 0 & 0 & 0 & 1 \\
\hline Videos September 09 & $30 \mathrm{~min}$ & NA & NA & 0 & 0 & 0 & 0 & NA & 0 & 0 & 0 & 0 & 0 & 0 \\
\hline Videos October 09 & in & NA & NA & 1 & 0 & 0 & 0 & NA & 0 & 0 & 0 & 0 & 0 & 0 \\
\hline Videos November 09 & total & NA & NA & 0 & 0 & 0 & 0 & NA & 0 & 0 & 0 & 0 & 0 & 0 \\
\hline April 10 & $4 \mathrm{~h}$ & NA & NA & 0 & NA & 0 & NA & NA & 0 & NA & 0 & 0 & 1 & 1 \\
\hline
\end{tabular}

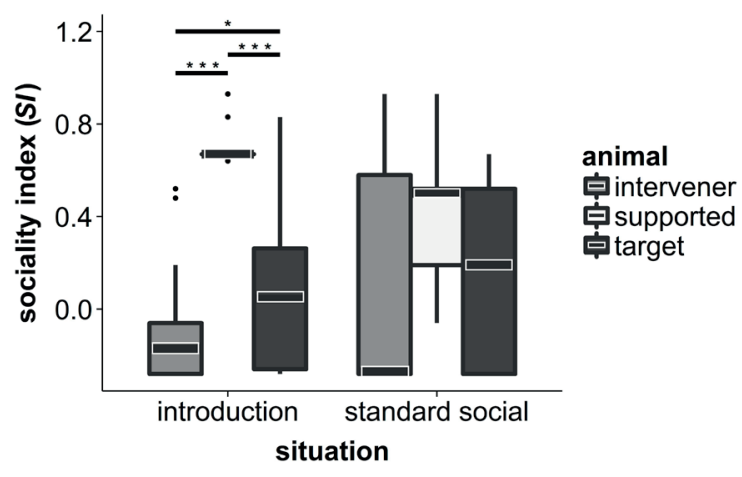

Fig. 3.

Differences in sociality indices between intervener, supported and targeted animals. The SI presents values between -1 and 1 , with a tendency towards -1 when more agonistic behaviour is displayed and a tendency towards 1 when more affiliative behaviour is displayed. Boxplots show the median, interquartile range, minimum, maximum and outliers (dots). In introduction situations intervener and targeted horses had a significant lower sociality index than supported animals (Wilcoxon signed rank test; intervener versus supported: $\mathrm{N}=28, \mathrm{~V}=0, \mathrm{P}<0.001$; intervener versus target: $\mathrm{N}=28, \mathrm{~V}=112, \mathrm{P}=0.04$, supported versus target: $\mathrm{N}=28, \mathrm{~V}=406, \mathrm{P}<0.001$ ). In standard social situations, only interveners showed a lower sociality index than supported animals, but the difference was not significant after Bonferroni correction. There was neither a significant difference in sociality index between intervener and target nor between supported and targeted animals (Wilcoxon signed rank test; intervener versus supported: $\mathrm{N}=12, \mathrm{~V}=12.5, \mathrm{P}=0.041$; intervener versus target: $\mathrm{N}=12, \mathrm{~V}=$ $39.5, P=1$, supported versus target: $N=12, V=53, P=0.289$ ). ${ }^{* * *} P<0.001$, ${ }^{*} P<0.05$ (after sequential Bonferroni correction). 


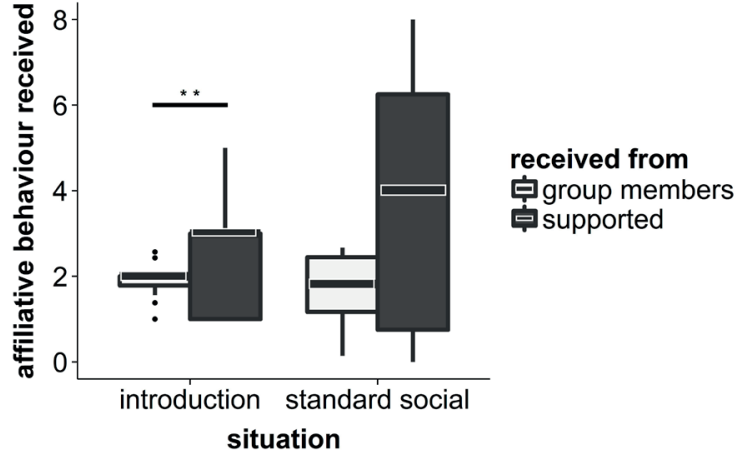

\subsection{Social Networks}

Furthermore, we analysed the animals' placement in their social behaviour networks, i.e. the frequency and direction of certain social behaviours displayed between the group members (Croft et al. 2008; Krause et al. 2015). For behaviour comparisons of intervention triads in introduction situations we used the behaviour displayed among the group members in the following standard social situation. The behaviours of standard social situation intervention triads were compared to the behaviours exchanged in the same situation.

We evaluated whether animals displayed more agonistic or more affiliative behaviour within their interaction network and named it 'Social Behaviour Index' (SI). The SI was evaluated as follows: we compared the individual animals' frequency of displaying affiliative behaviour versus its frequency of displaying agonistic behaviour. In social network terminology, we measured the outgoing affiliative and agonistic behaviour (out-degree) for each animal (Croft et al. 2008; Krause et al. 2015). For accounting for unequal interaction frequencies in the group, we averaged the affiliative and agonistic out-degree by calculating: (out-degree affiliative - out-degree agonistic) / (outdegree affiliative + out- degree agonistic). The resulting SI presents values between -1 and 1 , with a tendency towards -1 when more agonistic behaviour is displayed and a tendency towards 1 when more affiliative behaviour is displayed (Fig. 3).

\subsubsection{Alliances}

Furthermore, we analysed social bonds to determine alliance formation and protection in the bachelor horse group. It is assumed that social bonds in allied horse dyads are demonstrated by frequent exchange of affiliative interactions (Houpt and Boyd, 1994; Cameron et al., 2009; Schneider and Krueger, 2012), as was shown in primates (Silk et al., 2003; Fedurek and Dunbar, 2009) and many other species (for review see: Massen et al., 2010).

For analysing the alliances that may be present or may develop between the intervener and the supported animal, we compared the numbers of affiliative behaviours the intervener received from the supported animal against the average of affiliative behaviour it received from the other group members (Fig. 4). In network terminology, we compared the in-degree of affiliative behaviour for the
Fig. 4.

The numbers of affiliative behaviours interveners received from group members or supported animals.

Affiliative behaviours were counted in the following standard social situation after a particular intervention. Boxplots show the median, interquartile range, minimum and maximum. After intervening in introduction situations, the interveners received more affiliative behaviours from the supported animals than from other group members in the following standard social situation. ${ }^{* *} \mathrm{P}<0.01$

intervener it received from the supported animal versus the average of the in-degrees it received from the network members (Croft et al. 2008; Krause et al. 2015). The average of affiliative behaviours was calculated as follows: total number of affiliative behaviour the focus animal received from the group members without the supported animal divided by the number of group members -1 .

\subsection{Data analysis}

For statistical analysis and the depiction of the data we used the R-Project statistical environment (R Development Core Team, 2013). Most of the data were not normally distributed (K-S test). Binomial tests were applied for likelihood equations in binomial datasets. Friedman rank sum tests and Wilcoxon signed rank tests were used for comparing the median of dependent data sets. Because of the small sample size we used Kendall-tau-b correlation tests for pairwise correlations. All tests were two-tailed. The significance level was set at 0.05 with sequential Bonferroni corrections for multiple testing after Holm (1979).

\section{Table 2}

Number of observed intervention behavior into agonistic encounters of group members per horse and category (interv. = intervention, intro. = introduction situation, stand. soc. = standard social situation).

\begin{tabular}{llllll}
\hline Horse & ID & Date of birth & Total nr. Interv. & Interv. Introd. & Interv. Stand. Soc. \\
\hline Artos & 1 & 12.09 .00 & 1 & 0 & 1 \\
Chatgul & 4 & 06.05 .02 & 7 & 7 & 0 \\
Dimitri & 6 & 10.06 .03 & 19 & 13 & 6 \\
Salu & 7 & 07.05 .05 & 1 & 1 & 0 \\
Santos & 8 & 12.05 .05 & 4 & 3 & 1 \\
Fajacho & 9 & 22.05 .05 & 1 & 1 & 0 \\
Friso & 10 & 22.05 .05 & 0 & 0 & 0 \\
Aytan & 11 & 08.03 .06 & 4 & 3 & 1 \\
Gismo & 12 & 23.03 .06 & 0 & 0 & 0 \\
Branai & 13 & 14.11 .07 & 0 & 0 & 0 \\
Sitko & 14 & 15.09 .07 & 0 & 0 & 0 \\
Galwan & 15 & 20.11 .06 & 1 & 0 & 1 \\
Galsar & 16 & 12.08 .06 & 2 & 0 & 2 \\
Median & & & 1 & 0.5 & 0 \\
Range & & & $0-19$ & $0-13$ & $0-6$ \\
\hline
\end{tabular}

\section{Results}

\subsection{Occurrence of third-party intervention}

In total we observed 40 intervention triads in agonistic encounters of group mates, with individual horses displaying between 1 and 19 interventions each (table 1 and 2; table A.3). Eight of the 13 studied horses displayed 
third-party interventions. One horse, Dimitri, displayed most of the intervention behaviour $(\mathrm{N}=19)$. We observed 28 cases of intervention triads in introduction situations and 12 cases of intervention triads in standard social situations.

The whole group's agonistic behaviour level and the frequency of interventions throughout the whole study period tended to be positively, but insignificantly, correlated (Kendall-tau-b correlation test: interventions in agonistic encounters: $\mathrm{N}=13, \tau \mathrm{B}=0.424, \mathrm{P}=0.058$ ).

\subsection{Intervention for protection of kin or familiar individuals?}

As predicted, the stallions did not preferentially protect kin (table A.1) by intervention (Binomial test: $\mathrm{N}=40$, $\mathrm{P}=0.006$ ). From all possible intervention triads, the supported animal was related to the intervener in 11 triads, but unrelated in 29 triads.

In contrast to our expectations, animals known from previous housings (table A.2) were not supported preferentially (Binomial test: $\mathrm{N}=40, \mathrm{P}<0.001$ ). Only in one intervention triad did the intervening animal know the supported animal from previous housing.

\subsection{Were interventions reciprocated?}

As expected, interventions were not reciprocated in the observed intervention triads (Binomial test: $\mathrm{N}=40, \mathrm{P}<$ 0.001 ). For only one intervention triad did the supported animals reciprocate the aid later on.

\subsection{Relationship between interveners, supported and targeted animals of intervention triads}

For the evaluation of relationships between interveners, supported, and targeted animals we separated the intervention triads of introduction situations from those of standard social situations (table A.3). The relationship of the members of intervention triads may differ whether they are displayed towards a new and unknown animal in the introduction situations or towards a well-known animal in standard social situations.

\subsubsection{The social rank of intervening, supported and targeted animals}

In introduction situations and in standard social situations, the interveners supported animals that were lower in rank (introduction situations: median ADI intervener $=0.72$, min. $=0.33$, $\max .=0.89$; median ADI supported $=0.04$, $\min .=0, \max .=0.27$; Wilcoxon signed rank test: $\mathrm{N}=28$, $\mathrm{V}=406, \mathrm{P}<0.001 /$ standard social situations: median $\mathrm{ADI}$ intervener $=0.78, \min .=0.05, \max .=1 ;$ median ADI supported $=0.42$, min. $=0$, max. $=0.65$; Wilcoxon signed rank test: $\mathrm{N}=12, \mathrm{~V}=63.5, \mathrm{P}=0.006$; Fig. 2).

Interveners and targeted, threatening animals were of comparable social rank (introduction situations: median ADI intervener $=0.72$, min. $=0.33$, max. $=0.89$; median ADI target $=0.68, \min .=0, \max .=0.99 ;$ Wilcoxon signed rank test: $\mathrm{N}=28, \mathrm{~V}=226, \mathrm{P}=0.61 /$ standard social situations: median $\mathrm{ADI}$ intervener $=0.78, \mathrm{~min} .=0.05$, $\max .=1 ;$ median ADI target $=0.61$, min. $=0.1$, max. $=$ 1 ; Wilcoxon signed rank test: $\mathrm{N}=12, \mathrm{~V}=41, \mathrm{P}=0.91$; Fig. 2).

Targeted animals were higher in rank than the supported animals they threatened before the interveners interrupted (introduction situations: median ADI supported $=0.04$, min. $=0$, max. $=0.27$; median ADI target $=0.68$, min. $=0$, max. $=0.99$; Wilcoxon signed rank test: $\mathrm{N}=28, \mathrm{~V}=0, \mathrm{P}<$ 0.001 / standard social situations: median ADI supported $=0.42$, min. $=0, \max .=0.65 ;$ median ADI target $=0.61$, min. $=0.1$, $\max .=1$; Wilcoxon signed rank test: $\mathrm{N}=12, \mathrm{~V}$ $=6, \mathrm{P}=0.01$; Fig. 2).

\subsubsection{Changes in social rank of intervening, supported and targeted animals}

Neither after intervening in introduction situations nor in standard social situations did the interveners rise faster in rank than supported or targeted animals (introduction situation, median $\mathrm{ADI}$ increase: intervener $=0.01$, min. $=$ -0.004 , max. $=0.02$; supported $=0.003$, $\min .=0.003$, $\max$. $=0.04$; target $=0.004$, min. $=0$, max. $=0.04$; Friedman rank sum test: $\mathrm{N}=28, \mathrm{DF}=2, \chi^{2}=1.68, \mathrm{P}=0.43 /$ standard social situation, median ADI increase: intervener $=0.01$, min. $=0.002$, max. $=0.03 ;$ supported $=0.01$, min . $=0.004$, max. $=0.01 ;$ target $=0.01$, min. $=0.003$, $\max .=$ 0.02 ; Friedman rank sum test: $\mathrm{N}=12, \mathrm{DF}=2, \chi^{2}=1.17$, $\mathrm{P}=0.56$ ). Not even Dimitri, who intervened most often $(\mathrm{N}=19)$, rose significantly faster in rank than other group members, with an increase in his ADI of 0.012 .

\subsubsection{The interveners social network}

The animals intervening in introduction situations generally displayed more agonistic behaviour than affiliative behaviour (median $\mathrm{SI}=-0.17$, $\min .=-0.28$, $\max .=0.52$ ), the supported animals displayed more affiliative than agonistic behaviour (median SI $=0.67$, min. $=0.64$, $\max$. $=0.93$ ), and the targeted animals showed a tendency to display more affiliative than agonistic behaviour (median $\mathrm{SI}=0.04$, min. $=-0.28, \max .=0.83$; Fig. 3 ). The same is true for standard social situations, here again, interveners displayed more agonistic behaviour than affiliative behaviour (median SI $=-0.27$, $\min .=-0.28$, $\max .=0.93$ ), the supported animals displayed more affiliative than agonistic behaviour (median $\mathrm{SI}=0.5$, min. $=-0.06$, $\max$. $=0.93)$, and the targeted animals showed more affiliative than agonistic behaviour (median SI $=0.19$, $\mathrm{min}$. = -0.28 , max. $=0.67$ ). For statistical differences between interveners, supported and targeted animals: see Wilcoxon signed rank test at Fig. 3.

\subsubsection{Alliances between interveners and sup- ported animals}

The interveners which intervened in introduction situations received more affiliative behaviour from the animals they supported than from the other group members in the following standard social situation (median affiliative behaviour received: from supported $=3$, $\min .=1$, $\max$. $=5$; from group members without the supported $=2$, $\min$. $=1$. $\max .=2.57$; Wilcoxon signed rank test: $\mathrm{N}=28, \mathrm{~V}$ 
$=243, \mathrm{P}=0.001$; Fig. 4). In standard social situations, interveners did not receive significantly more affiliative behaviour from the supported animal than from the other group members in the same situation (median affiliative behaviour received: from supported $=4$, $\min .=0$, ax. $=$ 8 ; from group members without the supported $=1.82$, $\min$. $=0.14$, $\max .=2.67$; Wilcoxon signed rank test: $\mathrm{N}=12, \mathrm{~V}$ $=59, \mathrm{P}=0.13$; Fig. 4).

\section{Discussion}

In the present study on a bachelor group of semi-wild Przewalski horses, eight of 13 stallions engaged in thirdparty intervention with one stallion, Dimitri, intervening most often.

Contrary to earlier suggestions (Boyd, 1988), the horses in the study did not intervene to protect kin. This might simply reflect a lack of kin recognition, as horses are capable of individual recognition (Proops et al., 2009; Krueger and Flauger, 2011), but discrimination between unfamiliar kin and non-kin has not been demonstrated. Furthermore, in horses it is unlikely that intervention has evolved to protect kin as, in nature, the majority of offspring disperse from their natal groups before maturity and band together with kin only rarely (see for review, Ehardt and Bernstein, 1992). Earlier findings of kin protection in Przewalski horses may be a by-product of housing in zoological facilities (Boyd, 1988), where related animals continue to stay together.

Furthermore, our study did not demonstrate intervention in favour of former field-mates. This is surprising, as there is evidence for affiliations among young male horses. Some authors have suggested that the presence of "playmates" may postpone the dispersal of young males from their natal groups (Klingel, 1972; Rutberg and Keiper, 1993), but Berger (1986) could not support this notion. Furthermore, it has been reported that male horses may form long-lasting alliances before and after dispersing to bachelor bands at an early age (Rubenstein, 1982) and even maintain these alliances when taking over a harem together (Feh, 1999). However, for the present study, data on playmate alliances in the natal groups before the animals were brought to the study site were not recorded. A follow up study would be needed to evaluate whether allied and non-allied former field mates would protect each other differently when joining bachelor groups.

Moreover, we did not find reciprocity in intervention, as has been mentioned for other ungulates before (Jennings et al., 2009).

In the present study, not only high ranking animals intervened into agonistic encounters, as shown previously for Przewalski stallions (Zharkikh and Andersen, 2009), but interveners appeared to be of comparable social rank to the animals they targeted. Moreover, the expected benefits, in terms of a faster rise in social rank (de Waal, 1992; Clutton-Brock and Parker, 1995, Flack et al., 2005, 2006), did not emerge from intervention behaviour, as interveners did not rise faster in social rank than supported or targeted animals, neither in standard social nor in introduction situations. The lack of interveners rising in social rank may partially be caused by the fact that intervening horses were of higher social status than supported individuals, Still, they were not higher ranking than the targeted horses and even Dimitri, who intervened most often, rose in rank throughout the study on a comparable rate to other group members.

Others suggest that the personality of the animals may be decisive for whether they engage in group member activities by intervening or not (Granquist et al., 2012, von Rohr et al., 2012). We would have expected interveners to engage in friendly (affiliative) interactions with others frequently. Interestingly, in the present study, the fact that interveners directed more agonistic than affiliative behaviour towards their group members, whereas supported and targeted animals showed more affiliative than agonistic behaviour, may indicate that interveners do not feature outstanding social personalities, but primarily implement their own interest through interventions.

For the intervener, the reason for engaging in interventions appeared to differ between standard social and introduction situation, even though causalities may overlap to some extent. In standard social situations, they protected animals regardless of whether they received more affiliative behaviour from them than from other group members. It appears as if they did not support allied animals, but may have gained benefits from promoting group cohesion (Bernstein, 1976; Ehardt and Bernstein, 1992) and reducing social disruption within the group, as discussed for deer (Jennings et al. 2009) and primates (Ehardt and Bernstein, 1992; Flack et al., 2005, 2006; von Rohr et al., 2012). This interpretation is supported by the notion of interveners tending to be higher ranking than supported and targeted animals even though this tendency is not significant.

In introduction situations, male horses may have intervened mostly for alliance formation. .Interveners received more affiliative behaviour from the animals they supported during introductions in the following standard social situations. Interveners may have formed alliances for the future, as suggested in previous studies (Tilson, 1988; Schilder, 1990; Houpt and Boyd, 1994; VanDierendonck et al., 2009; Schneider and Krueger, 2012; Granquist et al., 2012).

Primate studies proved dominants to intervene for reducing aggression levels in standard social situations, by documenting enhanced aggression levels when the alpha animal was removed from the group (Flack et al 2005, 2006). But in contrast to studies in primates studies in Przewalski horses do not allow for such an experiment as we found that different middle-ranking group members intervene in turns. In this set-up, the aggression level may not rise when main interveners are removed because others would take over and display intervention behaviour.

\section{Conclusions}

In conclusion, we suggest that intervention behaviour in agonistic encounters of male Przewalski horses mostly serves the promotion of group cohesion and the reduction of social disruption within the group in standard social situations and mostly alliance formation in introduction situations. 


\section{Acknowledgements}

We thank Thomas Bugnyar, and Hans Klingel for helpful discussions, Kate Farmer for language corrections, Knut Krüger for help with the " $R$ " statistical environment, the Landschaftspflegeverband Mittelfranken and especially Verena Fröhlich for providing us with help, their facilities and a picture, and the Tierpark Hellabrunn and Tiergarten Nürnberg for providing us with test horses. Furthermore, we thank fife anonymous referees for their helpful suggestions for the improvement of the manuscript. This work was supported by the Bavarian Program of Realizing Equal Opportunities for Women in Research and Teaching (HWP II) at the University Regensburg 2010, the Dr. Peter Deubner Stiftung, and an Excellence Grant of the Bavarian Government.

We declare that all research presented in the manuscript was conducted in accordance with all applicable laws and rules set forth by their governments and institutions, and all necessary permits were in hand when the research was conducted.

\section{References}

Aureli, F., de Waal, F.B.M., 2000. Natural conflict resolution. Berkley.

Berger, J., 1986. Wild horses of the Great Basin. University of Chicago Press, Chicago.

Bernstein, I.S., 1976. Dominance, aggression and reproduction in primate societies. J. Theor. Biol., 60, 459-472.

Boyd L., 1988. The behaviour of Przewalski's horses. Ph.D. thesis. Cornell University, Ithaca, NY.

Cameron, E.Z., Setsaas, T.H. and Linklater, W.L., 2009. Social bonds between unrelated females increase reproductive success in feral horses. Proc. Natl. Acad. Sci. U.S.A., 106, 13850-13853.

Clutton-Brock, T., 2009. Cooperation between non-kin in animal societies. Nature, 462, 51-57.

Clutton-Brock, T.H. and Parker, G.A., 1995. Punishment in animal societies. Nature, 373, 209-216.

Connor, R.C., 1995. Altruism among non-relatives: alternatives to the ,Prisoner's Dilemma'. Trends Ecol. Evol., 10, 84-86.

Croft, D.P., James, R., and Krause, J. (2008). Exploring Animal Social Networks. Princton University Press, Princton.

de Waal, F.B., 1977. The organization of agonistic relations within two captive groups of Java-monkeys (Macaca fascicularis). Z. Tierpsychol., 44, 225-282.

de Waal, F.B.M., 1992. Coalitions as part of reciprocal relations in the Arnhem chimpanzee colony. In: A.H., Harcourt and F.B.M., de Waal (Eds.), Coalitions and Alliances in Humans and Other Animals. Oxford University Press, Oxford, pp. 233-257.

de Waal, F.B.M., 1982. Chimpanzee politics:power and sex among apes. Johns Hopkins University Press, Baltimore.

de Waal, F.B.M. and Luttrell, L.M., 1988. Mechanisms of social reciprocity in three primate species: Sym- metrical relationship characteristics or cognition? Ethol. Sociobiol., 9, 101-118.

Ehardt, C.L. and Bernstein, I.S., 1992. Conflict intervention behaviour by adult male macaques: structural and functional aspects. In: A.H., Harcourt and F.B.M., de Waal (Eds.), Coalitions and Alliances in Humans and Other Animals. Oxford University Press, Oxford, pp. 83-111.

Fedurek, P. and Dunbar, R.I.M., 2009. What Does Mutual Grooming Tell Us About Why Chimpanzees Groom? Ethology, 115, 566-575.

Feh, C., 1999. Alliances and reproductive success in Camargue stallions. Anim. Behav., 57, 705-713.

Feh, C., 2005. Relationships and Communication in Socially Natural Horse Herds. In: D. S., Mills and S. M.,, McDonnell (Eds.), The domestic horse : the origins, development, and management of its behaviour. Cambridge University Press 2005, Cambridge.

Feist, J. D., and McCullough, D. R., 1976. Behavior patterns and communication in feral horses. Z. Tierpsychol., 41, 337-371.

Flack, J.C., de Waal, F.B.M \& Krakauer, D.C. 2005. Social structure, robustness, and policing cost in a cognitively sophisticated species. American Naturalist, 165,126-139.

Flack, J.C., Girvan, M., de Waal, F.B.M. and Krakauer, D.C. 2006. Policing stabilizes construction of social niches in primates. Nature, 439, 426-429.

Frank S. A., 1996. Policing and group cohesion when resources vary. Anim. Behav., 52, 1163-1169.

Gouzoules, S. and Gouzoules, H., 1987. Kinship. In: B.B., Smuts, D.L., Cheney, R.M., Seyfarth, R.W., Wrangham and Struhsaker T.T (Eds.), Primate societies. University of Chicago Press, Chicago, pp. 299-305.

Granquist, S.M., Thorhallsdottir, A.G. and Sigurjonsdottir, H., 2012. The effect of stallions on social interactions in domestic and semi feral harems. Appl. Anim. Behav. Sci., 141, 49-56.

Hamilton, W.D., 1964. The genetical evolution of social behaviour. J. Theor. Biol., 7, 1-52.

Hemelrijk, C.K., Wantia, J. and Gygax, L., 2005. The construction of dominance order: comparing performance of five methods using an individual-based model. Behaviour, 142, 1043-1064.

Hinde, R.A., 1978. Dominance and role-two concepts with dual meanings. J. Soc. Biol. Struct., 1, 27-38.

Houpt, K.A. and Boyd L., 1994. Social Behaviour. In: Boyd L. and K.A., Houpt (Eds.), Przewalski's horse. State university of New York Press, Albany.

Jennings, D.J., Carlin, C.M. and Gammell, M.P., 2009. A winner effect supports third-party intervention behaviour during fallow deer, Dama dama, fights. Anim. Behav., 77, 343-348.

Klingel, H., 1972. The behavior of horses (Equidae). Handb. Zoolog., 8, 1-68.

Krause, J., James, R., Franks, D.W., and Croft, D.P., 2015. Animal Social Networks. Oxford University Press, Oxford. 
Krueger, K. and Flauger, B., 2011. Olfactory recognition of individual competitors by means of faeces in horse (Equus caballus). Anim. Cogn., 14, 245-257.

Linklater, W.L., 2000. Adaptive explanation in socio-ecology: lessons from the Equidae. Biol. Rev., 75, 1-20.

Linklater, W.L., Cameron, E.Z., Stafford, K.J. and Veltman, C.J., 2000. Social and spatial structure and range use by Kaimanawa wild horses (Equus caballus: Equidae). New Zealand J. Ecol., 24, 139-152.

Massen, J., Sterck, E., de Vos, H., 2010. Close social associations in animals and humans: functions and mechanisms of friendship. 1379.

McDonnell, S.M. and Haviland, J.C.S., 1995. Agonistic ethogram of the equid bachelor band. Appl. Anim. Behav. Sci., 43, 147-188.

Noë, R., 1992. Alliance formation among male hamadryas baboons: shopping for profitable partners. In: A.H., Harcourt and F.B.M., deWaal (Eds.), Coalitions and alliances in humans and other animals. Oxford University Press, Oxford, pp. 284-321.

Noë, R. and Hammerstein, P., 1994. Biological markets: supply and demand determine the effect of partner choice in cooperation, mutualism and mating. Behav. Ecol. Sociobiol., 35, 1-11.

K. and Kaukiainen, A., 1996. Bullying as a group process: Participant roles and their relations to social status within the group. Aggr. Behav., 22, 1-15.

Schilder, M.B.H., 1990. Interventions in a herd of semi - captive Plains zebras. Behaviour, 112, 53-83.

Schino, G., di Sorrentino, E.P. and Tiddi, B., 2007. Grooming and coalitions in Japanese macaques (Macaca fuscata): Partner choice and the time frame reciprocation. J. of Comp. Psychol., 121, 181-188.

Schneider, G. and Krueger, K., 2012. Third-party interventions keep social partners from exchanging affiliative interactions with others. Anim. Behav., 83, 377-387.

Schülke, O., Bhagavatula, J., Vigilant, L. and Ostner, J., 2010. Social Bonds Enhance Reproductive Success in Male Macaques. Curr. Biol., 20, 2207-2210.

Silk, J.B., 1992. Patterns of intervention in agonistic contests among male bonnet macaques. In: F.B.M., and de Waal, A.H., Harcourt (Ed.), Coalitions and Alliances in Humans and Other Animals. Oxford University Press, Oxford, pp. 215-232.

Silk, J.B., Alberts, S.C. and Altmann, J., 2003. Social Bonds of Female Baboons Enhance Infant Survival. Science, 302, 1231-1234.

Smith, J.E., Van Horn, R.C., Powning, K.S., Cole, A.R., Graham, K.E., Memenis, S.K. and Holekamp, K.E., 2010. Evolutionary forces favoring intragroup coalitions among spotted hyenas and other animals. Behav. Ecol., 21, 284-303.

Tilson, R.L., Sweeny, K.A., Binczik, G.A. and Reindl, N.J., 1988. Buddies and bullies: Social structure of a bachelor group of Przewalski horses. Appl. Anim. Behav. Sci., 21, 169-185.
Noë, R. and Hammerstein, P., 1995. Biological markets. Trends. Ecol. Evol, 10, 336-339.

Noë, R., van Schaik, C.P. and van Hooff, J.A.R.A.M., 1991. The Market Effect: an Explanation for Pay-off Asymmetries among Collaborating Animals. Ethology, 87, 97-118.

Packer, C., 1977. Reciprocal altruism in Papio anubis. Nature, 265, 441-445.

Proops, L., McComb, K. and Reby, D., 2009. Crossmodal individual recognition in domestic horses (Equus caballus). Proc. Natl. Acad. Sci. U.S.A., 106, 947-951.

R Development Core Team. 2013. R: A Language and Environment for Statistical Computing.http:// www.R-project.org. http://www.R-project.org.

Romero, T. and Aureli, F., 2008. Reciprocity of support in coatis (Nasua nasua). J. Comp. Psychol., 122, 19-25.

Rubenstein, D.I., 1982. Reproductive value and behavioral strategies: coming of age in monkeys and horses. Perspect. Ethol., 5, 469-487.

Rutberg, A.T. and Keiper, R.R., 1993. Proximate causes of natal dispersal in feral ponies: some sex differences. Anim. Behav., 46, 969-975.

Salmivalli, C., Lagerspetz, K., Björkqvist, K., Österman,

Trivers, R.L., 1971. The evolution of reciprocal altruism. Quart Rev Biol, 46, 35-57.

Tyler, S.J., 1972. The behaviour and social organisation of the new Forest ponies. Anim. Behav. Monogr., 5, 85-196.

VanDierendonck, M.C., de Vries, H., Schilder, M.B.H., Colenbrander, B. and Porhallsdóttir, A.G. and S., H., 2009. Interventions in social behaviour in a herd of mares and geldings. Appl. Anim. Behav. Sci., 116, 67-73.

von Rohr, C.R., Koski, S.E., Burkart, J.M., Caws, C., Fraser, O.N., Ziltener, A. and van Schaik, C.P., 2012. Impartial Third-Party Interventions in Captive Chimpanzees: A Reflection of Community Concern. PLoS ONE, 7, e32494 EP -

Ward, C., Trisko, R. and Smuts, B.B., 2009. Third-party interventions in dyadic play between littermates of domestic dogs, Canis lupus familiaris. Anim. Behav., 78, 1153-1160.

Widdig, A., Streich, W., Nürnberg, P., Croucher, P., Bercovitch, F. and Krawczak, M., 2006. Paternal kin bias in the agonistic interventions of adult female rhesus macaques (Macaca mulatta). Behav. Ecol. Sociobiol., 61, 205-214.

Zabel, C.J., Glickman, S.E., Frank, L.G., Woodmansee, K.B. and Keppel, G., 1992. Coalition formation in a colony of prepubertal spotted hyaenas. In: A.H., Harcourt and F.B.M., de Waal (Eds.), Coalitions and Alliances in Humans and Other Animals. Oxford University Press, Oxford, pp. 113-135.

Zharkikh, T.L. and Andersen, L., 2009. Behaviour of Bachelor Males of the Przewalski Horse (Equus ferus przewalskii) at the Reserve Askania Nova. Zoolog. Garten, 78, 282-299. 
Appendices

Table A.1

Relatedness as calculated from the pedigree of the Przewalski horses.

\begin{tabular}{|c|c|c|c|c|c|c|c|c|c|c|c|c|c|}
\hline & Artos & Chatgul & Dimitri & Salu & Santos & Fajacho & Friso & Aytan & Gismo & Branai & Sittko & Galwan & Galsar \\
\hline Artos & NA & 0 & 0 & 0 & 0 & 0 & 0 & 0 & 0 & 0.25 & 0 & 0 & 0 \\
\hline Chatgul & 0 & NA & 0 & 0 & 0 & 0 & 0 & 0 & 0 & 0 & 0 & 0 & 0 \\
\hline Dimitri & 0 & 0 & NA & 0 & 0 & 0.25 & 0 & 0 & 0,5 & 0 & 0 & 0 & 0 \\
\hline Salu & 0 & 0 & 0 & NA & 0.25 & 0 & 0 & 0.25 & 0 & 0 & 0.25 & 0 & 0 \\
\hline Santos & 0 & 0 & 0 & 0.25 & NA & 0 & 0 & 0.25 & 0 & 0 & 0 & 0 & 0 \\
\hline Fajacho & 0 & 0 & 0.25 & 0 & 0 & NA & 0 & 0 & 0.25 & 0 & 0 & 0 & 0 \\
\hline Friso & 0 & 0 & 0 & 0 & 0 & 0 & NA & 0 & 0 & 0 & 0 & 0 & 0.25 \\
\hline Aytan & 0 & 0 & 0 & 0.25 & 0.25 & 0 & 0 & NA & 0 & 0 & 0 & 0 & 0 \\
\hline Gismo & 0 & 0 & 0,5 & 0 & 0 & 0.25 & 0 & 0 & NA & 0 & 0 & 0 & 0 \\
\hline Branai & 0.25 & 0 & 0 & 0 & 0 & 0 & 0 & 0 & 0 & NA & 0.25 & 0 & 0 \\
\hline Sittko & 0 & 0 & 0 & 0.25 & 0 & 0 & 0 & 0 & 0 & 0.25 & NA & 0 & 0 \\
\hline Galwan & 0 & 0 & 0 & 0 & 0 & 0 & 0 & 0 & 0 & 0 & 0 & NA & 0 \\
\hline Galsar & 0 & 0 & 0 & 0 & 0 & 0 & 0.25 & 0 & 0 & 0 & 0 & 0 & NA \\
\hline
\end{tabular}

Table A.2

Numbers of days pairs of horses were kept together in previous zoo housing.

\begin{tabular}{|c|c|c|c|c|c|c|c|c|c|c|c|c|c|}
\hline & Artos & Chatgul & Dimitri & Salu & Santos & Fajacho & Friso & Aytan & Gismo & Branai & Sittko & Galwan & Galsar \\
\hline Artos & NA & 484 & 84 & 0 & 0 & 0 & 0 & 0 & 0 & 0 & 0 & 0 & 0 \\
\hline Chatgul & 484 & NA & 155 & 0 & 0 & 0 & 0 & 0 & 0 & 0 & 0 & 0 & 0 \\
\hline Dimitri & 84 & 155 & NA & 0 & 0 & 0 & 0 & 0 & 0 & 0 & 0 & 0 & 0 \\
\hline Salu & 0 & 0 & 0 & NA & 482 & 0 & 0 & 182 & 0 & 0 & 0 & 0 & 0 \\
\hline Santos & 0 & 0 & 0 & 482 & NA & 0 & 0 & 182 & 0 & 0 & 0 & 0 & 0 \\
\hline Fajacho & 0 & 0 & 0 & 0 & 0 & NA & 710 & 0 & 405 & 0 & 0 & $?$ & $?$ \\
\hline Friso & 0 & 0 & 0 & 0 & 0 & 710 & NA & 0 & 405 & 0 & 0 & $?$ & $?$ \\
\hline Aytan & 0 & 0 & 0 & 182 & 182 & 0 & 0 & NA & 0 & 0 & 0 & 0 & 0 \\
\hline Gismo & 0 & 0 & 0 & 0 & 0 & 405 & 405 & 0 & NA & 0 & 0 & $?$ & $?$ \\
\hline Branai & 0 & 0 & 0 & 0 & 0 & 0 & 0 & 0 & 0 & NA & 553 & 0 & 0 \\
\hline Sittko & 0 & 0 & 0 & 0 & 0 & 0 & 0 & 0 & 0 & 553 & NA & 0 & 0 \\
\hline Galwan & 0 & 0 & 0 & 0 & 0 & $?$ & $?$ & 0 & $?$ & 0 & 0 & NA & $?$ \\
\hline Galsar & 0 & 0 & 0 & 0 & 0 & $?$ & $?$ & 0 & $?$ & 0 & 0 & $?$ & NA \\
\hline
\end{tabular}

Table A 3.

Intervention triads listed by its observation date.

\begin{tabular}{|c|c|c|c|c|}
\hline Date & Intervener ID & Supported ID & Target ID & Situation \\
\hline 29.4.2008 & 4 & 12 & 10 & introduction \\
\hline 29.4.2008 & 4 & 12 & 9 & introduction \\
\hline 29.4.2008 & 4 & 12 & 1 & introduction \\
\hline 29.4.2008 & 4 & 12 & 10 & introduction \\
\hline 29.4.2008 & 4 & 12 & 10 & introduction \\
\hline 29.4.2008 & 4 & 12 & 6 & introduction \\
\hline 29.4.2008 & 6 & 12 & 1 & introduction \\
\hline 29.4.2008 & 4 & 12 & 6 & introduction \\
\hline 29.4 .2008 & 6 & 12 & 1 & introduction \\
\hline 29.4 .2008 & 6 & 12 & 9 & introduction \\
\hline 29.4.2008 & 6 & 12 & 1 & introduction \\
\hline 29.4.2008 & 6 & 12 & 1 & introduction \\
\hline 29.4.2008 & 6 & 12 & 10 & introduction \\
\hline 29.4.2008 & 6 & 12 & 1 & introduction \\
\hline 29.4.2008 & 6 & 12 & 1 & introduction \\
\hline 29.4.2008 & 6 & 12 & 1 & introduction \\
\hline 29.4.2008 & 7 & 12 & 11 & introduction \\
\hline 4.11 .2008 & 6 & 8 & 9 & stand_social \\
\hline 4.11 .2008 & 6 & 11 & 9 & stand_social \\
\hline 4.11 .2008 & 1 & 9 & 11 & stand_social \\
\hline 4.11 .2008 & 6 & 8 & 12 & stand_social \\
\hline 4.11 .2008 & 6 & 9 & 11 & stand_social \\
\hline 3.4 .2009 & 6 & 11 & 12 & stand_social \\
\hline 20.5.2009 & 9 & 13 & 8 & introduction \\
\hline 2.6.2009 & 11 & 14 & 8 & introduction \\
\hline 2.6.2009 & 8 & 14 & 11 & introduction \\
\hline 2.6.2009 & 8 & 14 & 11 & introduction \\
\hline 2.6.2009 & 11 & 14 & 6 & introduction \\
\hline 2.6.2009 & 8 & 14 & 11 & introduction \\
\hline 29.6.2009 & 11 & 15 & 8 & introduction \\
\hline 29.6.2009 & 6 & 15 & 14 & introduction \\
\hline 29.6.2009 & 6 & 15 & 13 & introduction \\
\hline 29.6.2009 & 6 & 15 & 7 & introduction \\
\hline 29.6.2009 & 6 & 15 & 9 & introduction \\
\hline 29.6.2009 & 8 & 7 & 11 & stand_social \\
\hline 29.6.2009 & 11 & 9 & 6 & stand_social \\
\hline $08 / 2009$ & 16 & 11 & 6 & stand_social \\
\hline 12.10 .2009 & 6 & 11 & 8 & stand_social \\
\hline 17.5.2010 & 16 & 15 & 6 & stand_social \\
\hline 17.5.2010 & 15 & 16 & 6 & stand_social \\
\hline
\end{tabular}

